\title{
Information and Communication Technologies in Foreign Language Teaching in Multinational Higher Education Environment of Mining Region
}

\author{
Roman Islamov ${ }^{1, *}$, Oksana Greenwald $^{1}$, and Nina Tunyova ${ }^{1}$ \\ ${ }^{1}$ Kemerovo State University, Institute of Philology, Foreign Languages and Mediacommunications, \\ Department of Foreign Languages, 650000, 6 Krasnaya st., Kemerovo, Russia
}

\begin{abstract}
Sustainable development of a coal mining region such as Kuzbass to a large extent depends on the high-level education of specialists provided by higher education establishments of the region. The article focuses on information and communication technologies (ICT) as an integral part of educational process at a tertiary education level that are reforming and advancing it towards the innovative rank satisfying the demands of the mining region industry. The current situation of forced distance learning because of coronavirus epidemics in the world made it necessary to look at ICT not as a supportive tool of an educator but as a meaningful agent of pedagogical interaction. The analysis of ICT function in higher education allows defining ICT as a subject of pedagogical interaction. Some of e-learning resources and applications are analyzed from the point of view of their capability and efficiency to conduct foreign language distance teaching, in particular in multinational student groups of Kemerovo State University.
\end{abstract}

\section{Introduction}

In recent decades, the informatization of a society stimulates the fast rate of the innovations in various spheres of life such as economy, production, management, medicine, education, culture, and so forth. Currently, the higher education system is actively following the dynamics of changes in the field of rendering knowledge and skills by implementation of new technologies, creation of educational information environment, the increase in competence of faculty members to the level which satisfies the demands of both students and the professional market.

The urgency of the research is determined by the following reasons. Firstly, information and communication technologies (ICT) are considered a powerful tool for educational change and reform; their ultimate objective is to advance the teaching and learning process [1]. Therefore, ICT is the main mechanism of the reformation and modernization of the higher education system aimed at the high-quality development of education, its availability, affordances and possibilities. The integration of ICT into the field of higher

*Corresponding author: $\underline{\text { r.islamov87@gmail.com }}$ 
education is the priority in the world and in the Russian Federation as well. For instance, there are some state legal documents such as the Federal development program of education, the National doctrine of education in the Russian Federation, and the Concept of modernization of Russian education, that proclaim the modification or full transformation of today's paradigm of education and creation of an essentially new one which is focused on the ideas of informatization and the humanization. Secondly, the epidemiologic situation of 2020 proves to be a serious challenge to education system. A simultaneous forced switch to distance learning conducted exclusively by means of ICT made all educational community re-estimate the part ICT play in education on a qualitatively new level - not only as a supportive and additional pedagogical tool but as a valid agent (or a subject) of educational process that determines the quality of training specialists for sustainable development of such mining region as Kuzbass. Thirdly, one of the characteristic features of higher education in Kuzbass is multinational composition of its student community that is represented by a wide range of nationalities, being both the citizens of Russia and some foreign countries such as Tajikistan, Kirgizia, Uzbekistan and others. The development of appropriate conditions for the dialogue of cultures is a top-priority concern of regional higher education establishments in order to promote interethnic and intercultural tolerance and prevent nationalism, extremism and any kind of xenophobia in multinational higher education environment. One of the most efficient ways for organizing the dialogue of cultures is by means of a foreign language course that is a compulsory subject of the curriculum for any specialty.

\section{Materials and methods}

The aforementioned reasons demand to assess the role of ICT in foreign language teaching in multinational higher education environment of a mining region. The goal assumes the consideration of the following issues:

1) to define the essence of ICT and their benefits for higher education;

2) to examine the ICT role in pedagogical interaction;

3) to identify ICT as a meaningful and efficient subject of pedagogical interaction in foreign language teaching in multinational higher education environment.

The material of the research is represented by theoretical and practical works in philosophy, social sciences, pedagogy, and foreign language teaching. The method of comparative analysis of the existing terminology was applied to the definitions of ICT and pedagogical interaction with the demonstration of the main characteristics of its subjects. The material of the research also includes a variety of e-learning resources and applications designed for foreign language teaching and learning. Some of them were analyzed and described from the point of view of their capability and efficiency to conduct foreign language distance learning in multinational student groups.

\section{Results and discussion}

To sum up the definitions of ICT from a number of sources, we may conclude that ICT are considered to be a set of procedures, processes, and hardware-software means and devices which are integrated with the purpose to gather, process, store, share, display, and use information as well as to allow people and organizations to interact in the digital world [2].

In education ICT is an umbrella term which is understood as communication devices, including TV/radio communications, cell phones, computers, software and hardware, satellite systems along with the different services (videoconferences or online courses) used 
for an access to the various information sources (electronic, printing, instrumental, and human ones) and the instruments of a cooperative activity directed to achieve a specific educational result [3]. Increasingly, ICT is being applied successfully in instruction, learning, and assessment. A number of previous studies have shown that an appropriate use of ICT can raise higher educational quality because ICT allow to provide the individualization of training, to choose the course of training proceeding from the students' abilities and interests, to use the information modeling of the considered processes and objects, to develop students' independence and their creative capabilities [Fu].

Therefore, we can conclude that ICT in higher education is conceived as integration of digital didactic means into the process of training specialists that allows to reach the level of informatization that opens almost boundless opportunities for the reformation and innovation of training activity, search the sources of knowledge unavailable earlier, creation of a uniform digital medium of interaction both between the educator and the student, or the student and artificial intelligence (i.e. the educational software which does not require "live" participation of the educator) (see figure 1).

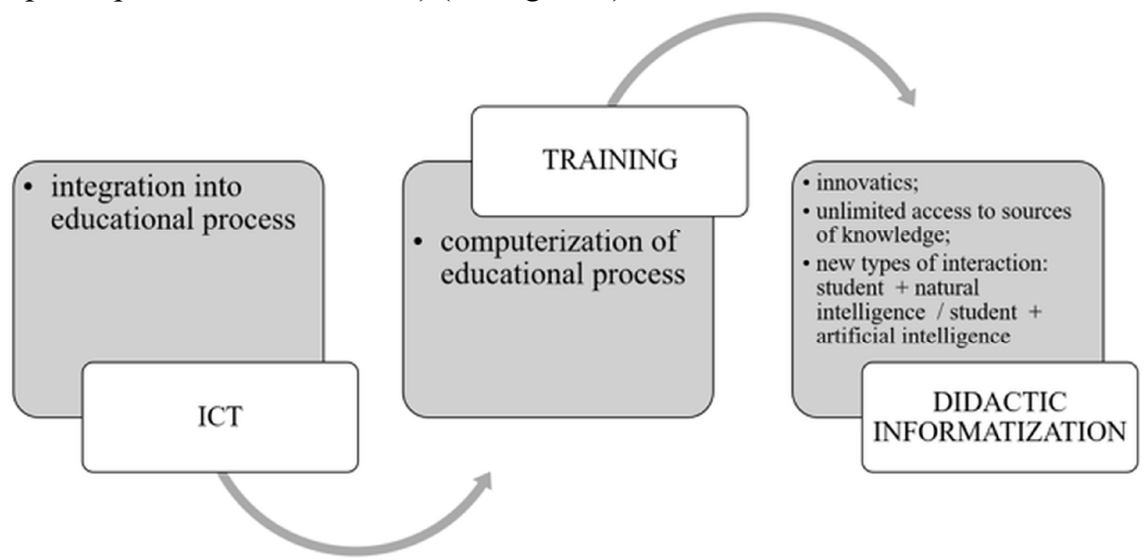

Fig. 1. ICT as a training modernization source.

Becoming an inherent part of educational process, ICT make us consider its role in pedagogical interaction, i.e. communicative, interactive and perceptual components of communication between the educator and the student.

The word interaction is derived from Latin inter - between and action - activity. It exists in different languages, e.g., ger. Interaktion, es. interacción, fr. interaction, etc. The fields where the term is used mainly include the humanities: psychology, philosophy, social sciences and pedagogics. Here the key concepts are individuals, social groups, their mutual influence as a continuous dialogue, the ability to represent oneself in the perception of other individual or group [4]. According to a German philosopher and sociologist J. Habermas, the level of the consent reached in communication process is measured by the value of transferred and demanded one by all the parties of the interaction. The sphere of interaction is a set of interpersonal relations which are significant for the subjects involved when the interaction bears value on its own [5].

However, this term can also be considered from a slightly different angle. According to the dictionary definition [6], the word interaction means a reciprocal action being a synonym to cooperation, i.e. the coherence of actions. Consequently, it is possible to say that the term interaction dominates in the differentiation of the goals of its subjects, e.g. an educator - a student. The educator's goal is to transfer knowledge and skills, whereas the student's goal is to acquire knowledge and skills. But if we speak about solidarity of goals 
for both parties, namely the realization of their didactic tasks, we get the interaction being considered as a coherence of actions for realization of such global goals.

For pedagogical interaction, both above-mentioned standpoints are important. American sociologist and social psychologist $\mathrm{H}$. Blumer notes that pedagogical interaction is "the interaction of subjects in educational process turning into collective behavior which obliges members of the group to submit to the general expectations and understanding of a social situation" [7].

Russian pedagogical science has also been working on this topic for a long time. For example, M. Petrenko defines pedagogical interaction as interactive technologies designed for training and developing the personality which are based on the purposeful and speciallyorganized group or intergroup activity for the achievement of educational goals. These technologies are based on the "feedback" between all participants of the activity for the achievement of mutual understanding and the correction of the educational and developing process as well as the individual style of communication on the basis of the reflexive analysis [8].

Thus, pedagogical interaction is always the purposeful activity based on the interpersonal interaction between educators and students when each participant is influenced by high-quality changes in the form of improvement and accumulation of new knowledge, abilities, skills, and competences toward the productive communication with other subjects of interaction for the achievement of the common / individual educational goals as well as for the achievement of a certain level of mutual understanding (see figure 2).

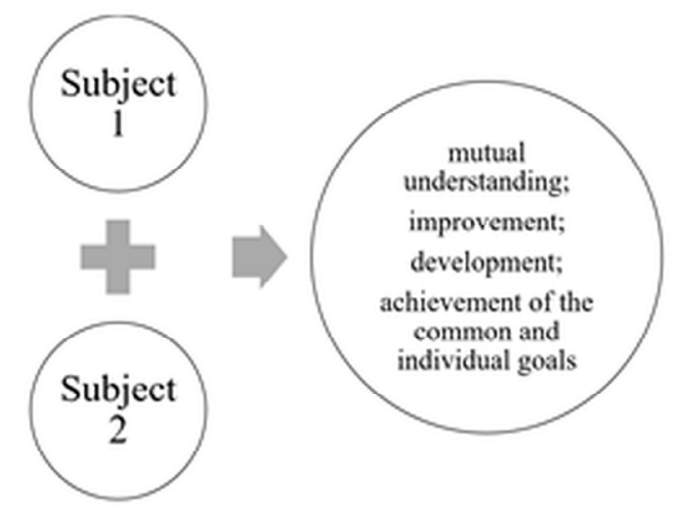

Fig. 2. The interactions.

As for the relations within any pedagogical interaction, they can be represented by two types: subject-subject and subject-object relations. These two types of relations in pedagogy originate from the philosophical concepts of a subject and an object. According to the philosophical interpretation, subject is (1) a thinking or feeling entity; the conscious mind; the ego, especially as opposed to anything external to the mind; it is (2) a person or an entity that has a relationship with another entity and can induce a specified feeling, response, or action [4].

What can be considered the subject of pedagogical interaction? For the purpose, we analyzed some material on this topic from the modern and historic perspective $[9,10,11]$ and came to the following conclusions:

The "subject-subject" pedagogical interaction is based on the principle of the equality of minds in relation to the truth. It is a dialogical form of communication. Sufficiently, it is an unpredictable form of interaction and reaction where the principle of feedback is fully 
dominating, i.e. the person listens, reacts, and changes his/her behavior in the course of communication depending on the perception of interlocutor's speech.

The "subject-object" pedagogical interaction presupposes a student is an object of pedagogical influence that reacts to the educator's actions. Pedagogical activity within the framework teacher-student inherently bears "subject-object" character because the student makes new discoveries, gains new knowledge in the course of training activity organized by the teacher. However, "subject-object" paradigm is rather about influence but not about interaction whereas knowledge and experience acquired by a student can be considered as an object of pedagogical interaction.

The aforesaid is leading us to the conclusion that the main form of interaction in educational process is the dichotomizing interrelation: "the educator's activity - the student's activity" and the subjects of pedagogical interaction are (i) an educator - a student, (ii) an educator -a students' group, and (iii) a student - a student (see figure 3 ).

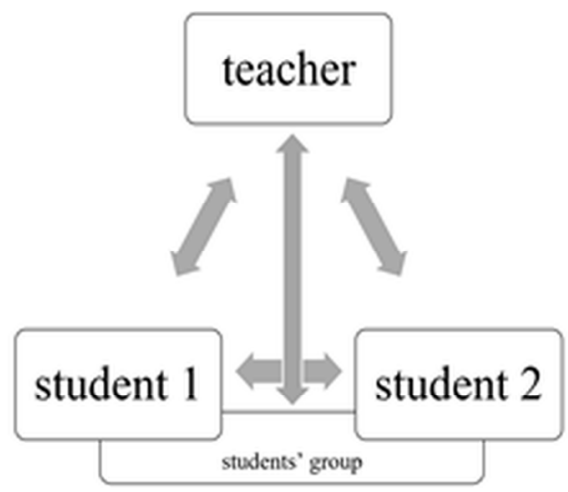

Fig.3. Subjects of pedagogical interaction.

Thus, the subject is a person (an educator) whose activity (teaching/training) is directed to other subject (a student/students' group) with the purpose to transfer a certain kind and amount of knowledge and skills by creating corresponding conditions and environment that facilitate the acquisition of those knowledge and skills by another subject (a student/students' group). What place do ICT have in this paradigm? Any educational computer program is designed by a person for a person and is intended to teaching (training) particular knowledge and skills. ICT include features, methods and techniques which are similar to those possessed and implemented by an educator. Furthermore, ICT have the potential for the creation of new educational content and techniques with artificial intelligence. Consequently, we may conclude that ICT are a subject of pedagogical interaction because they possess the characteristic features of the subject of pedagogical interaction, namely, an educator.

The next issue to be considered is whether ICT can be a meaningful and efficient subject of pedagogical interaction in foreign language teaching in multinational higher education environment of a mining region university. To create productive and positive atmosphere in multinational student groups it is urgent to promote social cultural adaptation of international students, their integration into social and educational life of the university, to shape all students' ethnical and intercultural tolerance, EFL course being a successful tool to achieve the purpose [12].

ICT in foreign language teaching and learning are represented by numerous computer programs and mobile applications. Some of them have already become the issue under consideration in our publications $[13,14,15]$. In this article we offer examples of ICT that were used during the period of distance foreign language learning because of coronavirus 
epidemics in 2020 in multinational student groups of Kemerovo State University, a leading higher educational establishment in Kuzbass. We divided the ICT used into 3 categories: 1) video conferencing services, 2) web services for creating interactive tasks with automatic evaluation, 3) LMS for managing, tracking, reporting, and delivering educational courses or training programs.

\section{Conclusion}

In conclusion, the current research establishes that informatization of higher education in Kuzbass through the implementation of ICT leads to its modernization and reforming at the didactic level that meets the requirements to higher education in the 21 st century, thus promoting the sustainable development of the region. The described ICT prove to be an efficient and productive subject of pedagogical interaction in foreign language teaching and learning in multinational student groups of the university because:

(1) ICT make foreign language knowledge acquisition more accessible providing the individualization of training from the perspective of students' mother tongue along with their abilities and motivation;

(2) ICT offer valuable and diverse material to examine social and cultural reality not only of the language studied but of international students' social and cultural background as well;

(3) ICT promote collaborative learning in case of distance education and enable students not only to acquire knowledge together but to communicate, share diverse learning experiences, work together and take control of their learning through their use of ICT. Besides, ICT allow organizing the dialogue of cultures by arranging students' collaborative activity over special problem-oriented projects thus preventing cross-cultural misunderstanding;

(4) ICT increase students' motivation and satisfaction with foreign language learning, thus mastering students' foreign language competence.

\section{Acknowledgement}

The reported study was funded by RFBR according to the research project № 19-01300805

\section{References}

1. J. Fu, IJEDICT, 9, 112-125 (2013)

2. The official and trusted source of internationally-comparable data on education, science, culture and communication (UIS, Washington, 2013)

3. K. Akarowhe, American Journal of Computer Science and Information Technology, $\mathbf{5 : 2}(2017)$

4. S. Blackburn, The Oxford Dictionary of Philosophy (McMillan, London, 2016)

5. J. Habermas, Suhrkamp, 606, 22 (1984)

6. Oxford Dictionary of English (McMillan, London, 2010)

7. H. Blumer, New Outline of the Principles of Sociology (Logan, New York, 1951)

8. M. Petrenko, ASOU, 2, 788-796 (2015)

9. A. Ben-Zeev, Social Research, 56 511-542 (1989)

10. H. Bliss, Philosophical Review, 26 395-408 (1917) 
11. C. Peirce, The Scientific and Philosophical Correspondence, 12, 65 (2009)

12. O. Greenwald, A. Resenchuck, T. Sergeychick, E3S Web Conf., 105, 04019 (2019)

13. R. Islamov, O. Greenwald, N. Tunyova, E3S Web Conf., 41, 04041 (2018)

14. R. Islamov, O. Greenwald, E3S Web Conf., 105, 04024 (2019)

15. A. Perevalova, E3S Web Conf., 41, 04030 (2018) 